\title{
STUDI POSISI LAYOUT DERMAGA PENDIDIKAN POLITANI DI PANTAI MANDALLE KABUPATEN PANGKEP
}

\author{
Irawan Alham ${ }^{1)}$, Irwan') dan Amir Yusuf ${ }^{3)}$ \\ ${ }^{1}$ Politeknik Pertanian Negeri Pangkajene Kepulauan \\ Email : irawanal@gmail.com \\ ${ }^{2}$ Politeknik Pertanian Negeri Pangkajene Kepulauan \\ Email:irwan@gmail.com \\ ${ }^{3}$ Politeknik Pertanian Negeri Pangkajene Kepulauan \\ Email : amiryusuf@gmail.com
}

\begin{abstract}
Abstrak
Politeknik Pertanian Negeri Pangkajene Kepulauan perlu memiliki dermaga pendidikan. Keberadaan dermaga bisa sebagai tempat tambat kapal latih Politani dan menunjang praktikum dua prodi baru di jurusan penangkapan ikan yaitu prodi teknik kelautan dan prodi pelabuhan dalam hal pelaksanaan praktikum dan survey oceanografi. Posisi dermaga yang baik merupakan salah satu faktor keberhasilan pembangunan dermaga pendidikan. Penelitian ini bertujuan untuk mengetahui posisi dermaga yang baik dan cocok diterapkan dilokasi pantai dibelakang kampus Politani.

Pengambilan data dilakukan pada bulan mei sampai bulan juli tahun 2019. Pengambilan data diawali dengan pengambilan data pasang surut dilokasi kegiatan selama 15 hari dengan interval pembacaan 1 jam untuk mengetahui tunggang pasang surutnya. Setelah itu dilakukan survei batimetri seluas $500 \times 1000 \mathrm{~m}^{2}$. Pengambilan data sekunder juga dilakukan yakni pengambilan data angin untuk analisis arah dan tinggi gelombang.

Hasil analisis survei batimetri menunjukkan bahwa perairan lokasi dermaga pendidikan Politani sangat landai dan panjang kelandaian cukup jauh kedepan arah laut. Kemiringan garis pantai sampai \pm 400 meter ke arah laut masih sangat kecil yakni hanya sekitar 0,43\%. Area kiri dan kanan jetti atau groin eksisting juga sangat landai dengan kemiringan kurang lebih sama. Pengukuran pada radius 800 meter dari garis pantai baru menunjukkan kedalaman yang cukup besar yakni sekitar 3,00 sampai 4,00 meter. Berdasarkan pertimbangan tunggang pasang surut yakni sekitar 2,03 meter dan draft kapal maksimal 1,5 meter maka dermaga harus jauh menjorok ke laut (model jetty) yakni sampai pada jarak 850 meter dari garis pantai dengan kondisi kedalaman 3,5 meter dari LWS.
\end{abstract}

Kata kunci: batimetri; dermaga; gelombang; pasang surut

\begin{abstract}
Pangkajene Islands State Agricultural Polytechnic needs to have an education dock. The existence of the pier can be used as a place for mooring of Politani training vessels and to support the practicum of two new study programs in the fishing department, namely marine engineering study program and port study program in terms of practicum and oceanographic survey. The good pier position is one of the factors in the success of the education pier development. This study aims to determine the good position of the pier and suitable to be applied at the beach location behind the Politani campus.

Data collection was carried out in May until July 2019. Data collection was initiated by taking tidal data at the location of activities for 15 days with 1 hour reading intervals to determine the tide ride. After that the bathymetry survey area of $500 \times 1000 \mathrm{~m} 2$. Secondary data retrieval is also carried out namely the collection of wind data for direction and wave height analysis
\end{abstract}


The results of the bathymetry survey show that the waters of the Politani education pier are very gentle and the length of the slope is quite far towards the sea. The slope of the coastline up to \pm 400 meters towards the sea is still very small at only $0.43 \%$. The left and right areas of the existing jetti or groin are also very gentle slope with approximately the same slope. Measurements at a radius of 800 meters from the new coastline show a fairly large depth of around 3.00 to 4.00 meters. Based on the consideration of tides which is around 2.03 meters and the draft of the ship is a maximum of 1.5 meters, the pier must be far jutting into the sea (jetty model), which is up to a distance of 850 meters from the coastline with a depth of 3.5 meters from the LWS.

Keywords: bathymetry; dock; wave; tidal

\section{Pendahuluan}

\section{Latar Belakang}

Politeknik Pertanian Negeri

Pangkajene dan Kepulauan memiliki 3 (tiga) unit kapal latih, ketiga kapal tersebut selama ini berlabuh di Pelabuhan Awerange kabupaten Barru, yang berjarak sekitar 17 KM dari kampus Politeknik Pertanian Negeri Pangkajene dan Kepulauan, kondisi tersebut menyebabkan pengamanan terhadap kapal menjadi memiliki kekurangan maksimal dan memerlukan biaya tambahan untuk petugas jaga malam disaat kapal berlabuh. Disamping hal tersebut di atas keberadaan dermaga pendidikan juga dibutuhkan dalam hal tempat praktikum mahasiswa tentang kepelabuhanan dan teknik kelautan dan serta merupakan sarana yang bisa ditata dengan prasarana lain disekitarnya seperti tambak, taman taman mangrove dan lain - lain supaya saling mendukung.

Salah satu faktor teknis yang mendukung keberhasilan dermaga ini adalah posisi layout dermaga. Posisi dermaga ini harus meminimalkan dampak negatif terhadap kapal yang sandar di dermaga, perubahan alur sedimentasi erosi yang terjadi di pantai, perubahan penjalaran gelombang dan lain - lain. Posisi dermaga yang baik akan memudahkan kapal bersandar pada dermaga dan cenderung konstruksinya akan bertahan lebih lama. Posisi dermaga juga harus memperhatikan kedalaman kolam labuh kapal. Kedalaman ini harus mempertimbangkan jenis - jenis kapal rencana yang akan sandar beserta draft kapal maksimum.
Lokasi pembangunan dermaga pendidikan di Pantai mandalle cukup landai sehingga memerlukan trestel yang cukup panjang. Hal ini akan berdampak pada biaya konstruksi yang besar. Selain itu kondisi pantai yang landai menyebabkan energi gelombang cukup besar karena gelombang sampai pada kondisi pecah. Melihat kenyataan itu maka sangat perlu diperhatikan posisi penempatan dermaga pendidikan Politani agar dapat meminimalkan dampak negatif pada dermaga.

\section{Metodologi}

\subsection{Survey Batimetri}

Untuk menentukan posisi dermaga maka hal yang penting dilakukan adalah mengetahui bentuk muka tanah di bawah permukaan air laut. Pengukuran bathimetri menggunakan alat GPSmap Sounder 585 yang dipasang di perahu. Dalam pelaksanaan pengukuran dengan GPSmap Sounder 585, selain pengambilan elevasi kedalaman laut dan koordinat titik elevasi tersebut, dilakukan juga tracking untuk mendapatkan penggambaran jalur dari pengukuran bathimetri. Selama pelaksanaan survey bathimetri juga dilakukan pengamatan pasang surut dengan interval waktu 10 menit.

Peralatan yang digunakan dalam pelaksanaan kegiatan survey bathimetri adalah sebagai berikut :

1) Garmin GPSmap Sounder 585 untuk mendeteksi kedalaman 
dan tampilan permukaan dasar laut.

2) Antena receiver untuk penerima sinyal dari satelit.

3) Transduser untuk penerima sinyal pantulan dari dasar perairan.

4) Komputer notebook untuk mengunduh data dari Garmin GPSmap Sounder 585.

5) Perahu untuk membawa peralatan dan operator.

6) Rambu pasut (peilschaal) untuk pengamatan pasang surut bersamaan dengan pelaksanaan survey bathimetri.

Pelaksanaan survey bathimetri dilakukan dengan lajur pengukuran diambil interval 50-100 meter dengan interval save tracking tiap 10 meter. Selama pengukuran bathimetri, dilakukan pengamatan pasang surut tiap 10 menit sebagai koreksi kedalaman. Data bathimetri yang didapat dari pengukuran, selanjutnya diikatkan pada bacaan elevasi muka air dari pengamatan pasang surut untuk waktu yang sama. Pengamatan pasang surut sendiri diikatkan dengan elevasi semua Titik Tetap (benchmark) di darat, sehingga data bathimetri mempunyai referensi datum yang sama dengan data pasang surut. Pemetaan topografi dan batimetri dilakukan di sekitar rencana lokasi pelabuhan, meliputi seluruh kawasan yang diperlukan untuk keperluan perancangan pelabuhan. Hasil pengukuran bathimetri dan topografi dipetakan menjadi satu peta dengan datum \pm 0.00 LWS.

\subsection{Survey Pasang Surut}

Pengamatan pasang surut harus dilakukan untuk mengetahui karakteristik pasang surut di daerah studi. Pengetahuan tentang pasang surut berguna dalam menentukan elevasi muka air rencana. Dalam perencanaan konstruksi bangunan pelabuhan, hal ini terkait dengan penentuan elevasi puncak bangunan seperti elevasi deck dermaga. Pengamatan dilakukan di Pantai
Mandalle atau disekitar area dermaga pendidikan Politani. Pelaksanaan pengamatan pasang surut sudah dilaksanakan selama 15 hari mulai pukul 00:00 sampai dengan pukul 23:00 waktu setempat (24 jam). Dalam rentang pengamatan tersebut diperoleh pasang naik saat bulan baru.

Rambu pasut (peilschaal) merupakan papan bacaan yang terdiri dari angka-angka yang dapat dibaca, menunjukkan ketinggian air pada suatu waktu. Bahan rambu pasang surut (peilschaal) dibuat dari balok sebagai tiang skala yang ditancapkan pada titik survey pasang surut. Titik balok ini di pasang sebanyak dua buah agar ada pembanding bacaan tinggi muka air.Peralatan yang digunakan dalam pengamatan pasang surut adalah sebagai berikut :

1) Rambu pasut (peilschaal) untuk mengetahui tinggi muka air laut, yang diukur dari suatu datum tertentu.

2) Garmin GPS 78s untuk menentukan koordinat rambu pasang surut (peilschaal).

3) Waterpass Topkon AT-B4 untuk mengikat rambu pasang surut (peilschaal) ke patok ukur dan BM topografi.

4) Senter untuk membantu penerangan malam hari saat melihat angka di rambu pasang surut (peilschaal).

5) Formulir pengamatan pasang surut dan alat tulis untuk mencatat hasil pengamatan.

Pengamatan pasang surut dilakukan dengan pembacaan secara manual dengan mengamati secara langsung tinggi muka air pada suatu waktu dan mencatat angka yang tertera pada rambu pasang surut (peilschaal) yang menunjukkan elevasi muka air pada rambu pasang surut (peilschaal). Pengamatan dilakukan tiap 1 jam selama satu siklus bulan (15 hari).

\subsection{Survey Topografi}

Survey topografi ini bertujuan untuk menggambarkan bentuk muka daratan di sekitar lokasi dermaga. Peta 
ini juga memperlihatkan perbedaan elevasi atau ketinggian daratan di sekitar area dermaga. Kegiatan survey topografi menggunakan alat ukur sudut (Total Station) dan alat penyipat datar (waterpass). Pengukuran penampang melintang pantai dilakukan sepanjang garis pantai di depan area darat sepanjang \pm 150 meter. Jarak antar penampang melintang sejauh 20 meter. Pengukuran dimulai dari garis pantai ke arah tengah laut sampai batas surut air laut. Area di depan batas surut merupakan kedalaman yang tidak memungkinkan dilakukan pengukuran topografi maka dilakukan pengukuran bathimetri menggunakan alat echosounder.

Peralatan yang digunakan dalam survey topografi adalah sebagai berikut :

1) Total Station Nikon DTM-322

2) Waterpass Wild Ni2

3) Statip/Trifoot

4) Bak Ukur

5) Jalon

6) Prisma

7) Pita Ukur $50 \mathrm{~m}$

8) Formulir data ukur dan alat tulis untuk mencatat hasil bacaan

9) Kalkulator scientific untuk perhitungan data di lapangan

\section{A. Pengukuran Poligon}

1. Pengukuran Sudut

- Sistem pengukuran ialah poligon tertutup.

- Metoda pengukuran 2 seri dimana setiap seri dibaca biasa dan luar biasa.

- Peralatan yang digunakan Nikon Total Station DTM-322.

2. Pengukuran Jarak

- Metoda pengukuran ialah pergi pulang masing-masing dilakukan 2 (dua) kali pembacaan.

- Untuk kontrol jarak dilakukan pengecekan dengan menggunakan pita ukur.

\section{B. Sifat Datar}

Pengukuran sipat datar dilakukan pada setiap patok batas area berupa patok BPN. Alat yang digunakan adalah Waterpass Wild Ni2.

\section{4 . Survey Arus dan gelombang}

Pembentukan gelombang di laut dalam, dianalisa dengan formulaformula empiris yang diturunkan dari model parametrik berdasarkan spektrum gelombang JONSWAP (Joint North Sea Wave Project) (CERC, 1984). Prosedur peramalan tersebut berlaku baik untuk kondisi fetch terbatas (fetch limited condition) maupun kondisi durasi terbatas (duration limited condition).

Pada kondisi fetch terbatas, angin bertiup secara konstan cukup jauh untuk tinggi gelombang di ujung fetch dalam mencapai keseimbangan sedangkan pada kondisi durasi terbatas, tinggi gelombang dibatasi waktu setelah angin bertiup/berhembus.Spektral tinggi gelombang signifikan (H0) dan periode puncak spektrum (Tp).

Sedangkan arus dilakukan survey secara langsung di perairan Mandalle. Pengamatan arus dilakukan pada dua lokasi menggunakan alat current meter atau floater yang dilakukan pada saat pasang tertinggi (Spring Tide) dan pada saat surut terendah (Neap Tide) pada bulan yang sama. Jika memungkinkan data arus ditampilkan dalam aplikasi simulasi arus dengan menggunakan perangkat komputer.

\section{Hasil dan Pembahasan}

\section{Analisis Kompilasi Data}

Analisis beberapa parameter oseanografi pada sub bab diatas dapat membantu peneliti untuk menentukan posisi layout Dermaga Pendidikan Politani. 
Rumusan berpikir atau alur pertimbangannya sebagai berikut:

\section{Pasang surut}

Hasil survey pasang surut menujukkan tunggang pasang surut sebesar 2,03 meter dan surut terendah terjadi pada jarak 215 meter dari garis pantai. Analisis data tersebut menyampaikan bahwa posisi dermaga masih harus maju ke arah laut menjauhi posisi surut terendah atau lebih dari 215 meter dari garis pantai.

\section{Spesifikasi kapal}

Draft Kapal Latih Politani atau sarat maksimal ketika kapal bermuatan penuh adalah 1,50 meter. Data pasang surut dan data spesifikasi kapal ini menyampaikan bahwa posisi dermaga harus berada pada kedalaman yang mempertimbangkan tunggang pasang dan draft kapal yaitu sebesar

\section{1,50}

$$
\text { Hdermaga }=2,03+
$$

$$
\text { meter dari LWS }
$$

$$
=3,53
$$

3. Survey Batimetri.

Hasil survey batimetri menunjukkan pantai lokasi rencana dermaga pendidikan sangat landai. Kelandaian cukup jauh kedepan dengan besar kemiringan sekitar $0,43 \%$. Pada peta batimetri kedalaman dermaga yang besarnya 3,53 meter dari LWS berada pada jarak 850 meter dari garis pantai. Sehingga disarankan posisi dermaga pendidikan berada jarak 850 meter dari garis pantai. Hasil batimetri menujukkan kedalaman disekitar groin eksisting sangat landai sehingga agar groin eksisting tidak dibongkar maka sepanjang groin eksisting dijadikan causeway dermaga. Setelah causeway direncanakan struktur trestel sampai pada jarak 850 meter.

\section{Gelombang}

Hasil hindcasting gelombang menunjukkan gelombang tahunan dipantai mandalle gelombang cukup besar datang dari arah barat daya (SW) dan barat (W), maka disarankan dermaga berbentuk huruf $\mathrm{L}$ dengan sisi samping menghadap ke utara dan daerah belakang dermaga berbentuk kolam labuh. Posisi seperti ini memungkinkan kapal sandar dengan aman pada bagian utara dan dibagian belakang dermaga jika sewaktu waktu gelombang datang dari barat daya dan barat.

Agar lebih mudah dipahami maka

\begin{tabular}{|c|c|c|c|c|}
\hline No & $\begin{array}{l}\text { Variabel } \\
\text { Penilaian }\end{array}$ & Uraian & Rekomendasi & Keterangan \\
\hline 1. & Bathimetri & $\begin{array}{l}\text {-Hasil survei topografi } \\
\text { batimetri menunjukkan } \\
\text { perairan lokasi dermaga } \\
\text { pendidikan sangat landai } \\
\text { dan panjang kelandaian } \\
\text { cukup jauh kedepan } \\
\text { arah laut. } \\
\text {-Kemiringan garis pantai } \\
\text { sampai } \pm 350 \text { meter ke } \\
\text { arah laut masih sangat } \\
\text { kecil yakni hanya sekitar } \\
0,43 \% \text {. Area kiri dan } \\
\text { kanan jetti atau groin } \\
\text { eksisting juga sangat }\end{array}$ & $\begin{array}{l}\text { - Dermaga pendidikan } \\
\text { berbentuk jetty yang } \\
\text { menjorok jauh } \\
\text { kedepan. } \\
\text { - Groin eksisting } \\
\text { dijadikan sebagai } \\
\text { causeway dari } \\
\text { pasangan batu supaya } \\
\text { tidak dilakukan } \\
\text { pembongkaran groin } \\
\text { eksisting } \\
\text { - Konstruksi dermaga } \\
\text { menggunakan trestle }\end{array}$ & \\
\hline
\end{tabular}
rumusan berpikir ini kami tuangkan dalam bentuk matriks sebagai berikut: 


\begin{tabular}{|c|c|c|c|c|}
\hline & & $\begin{array}{l}\text { landai dengan } \\
\text { kemiringan kurang lebih } \\
\text { sama. } \\
\text {-Pengukuran pada radius } \\
800 \text { meter dari garis } \\
\text { pantai baru } \\
\text { menunjukkan kedalaman } \\
\text { yang cukup besar yakni } \\
\text { sekitar 3,00 sampai 3,5 } \\
\text { meter. }\end{array}$ & $\begin{array}{l}\text { dengan struktur tiang } \\
\text { beton sampai pada } \\
\text { jarak } 850 \text { meter dari } \\
\text { garis pantai atau } \\
\text { sekitar } 500 \text { meter dari } \\
\text { groin eksisting }\end{array}$ & \\
\hline 2. & $\begin{array}{l}\text { Pasang } \\
\text { Surut dan } \\
\text { draf kapal }\end{array}$ & $\begin{array}{l}\text { - Tunggang Pasang Surut } \\
203 \mathrm{~cm} \text { (pembacaan } \\
\text { level terendah } 61 \mathrm{~cm} \\
\text { dan maksimum } 264 \mathrm{~cm}) \\
\text { m dimana surut terendah } \\
\text { berada pada jarak } 215 . \\
\text { Draf kapal } \\
\text { - } \text { meter dari garis pantai. } \\
\text { Draf kapal pada saat } \\
\text { muatan penuh adalah } 1,5 \\
\text { meter }\end{array}$ & $\begin{array}{l}\text { a pasang surut dan data } \\
\text { spesifikasi kapal ini } \\
\text { menyampaikan } \\
\text { bahwa posisi } \\
\text { dermaga harus berada } \\
\text { pada kedalaman } \\
\text { kedalaman yang } \\
\text { mempertimbangkan } \\
\text { tunggang pasang dan } \\
\text { draft kapal yaitu } \\
\text { sebesar } 3,53 \text { meter } \\
\text { dari low water sea } \\
\text { (LWS) }\end{array}$ & \\
\hline 3. & $\begin{array}{l}\text { Arah dan } \\
\text { tinggi } \\
\text { gelombang }\end{array}$ & $\begin{array}{l}\text { - Hasil hindcasting } \\
\text { gelombang } \\
\text { menunjukkan } \\
\text { gelombang tahunan } \\
\text { dipantai mandalle } \\
\text { gelombang cukup besar } \\
\text { datang dari arah barat } \\
\text { daya (SW) sebesar } 1,49 \\
\text { dan barat (W) sebesar } \\
1,29 \text { pada periode } 20 \\
\text { tahun }\end{array}$ & $\begin{array}{l}\text { rrankan dermaga } \\
\text { berbentuk huruf } \mathrm{L} \\
\text { dengan sisi samping } \\
\text { menghadap ke utara } \\
\text { dan daerah belakang } \\
\text { dermaga berbentuk } \\
\text { kolam labuh. } \\
\text { si seperti ini } \\
\text { memungkinkan kapal } \\
\text { sandar dengan aman } \\
\text { pada bagian utara dan } \\
\text { dibagian belakang } \\
\text { dermaga jika sewaktu } \\
\text { waktu gelombang } \\
\text { datang dari barat daya } \\
\text { dan barat. }\end{array}$ & - \\
\hline
\end{tabular}

Dari hasil analisis posisi dermaga tersebut maka kami setelah dituangkan dalam gambar layout hasilnya sebagai berikut: 


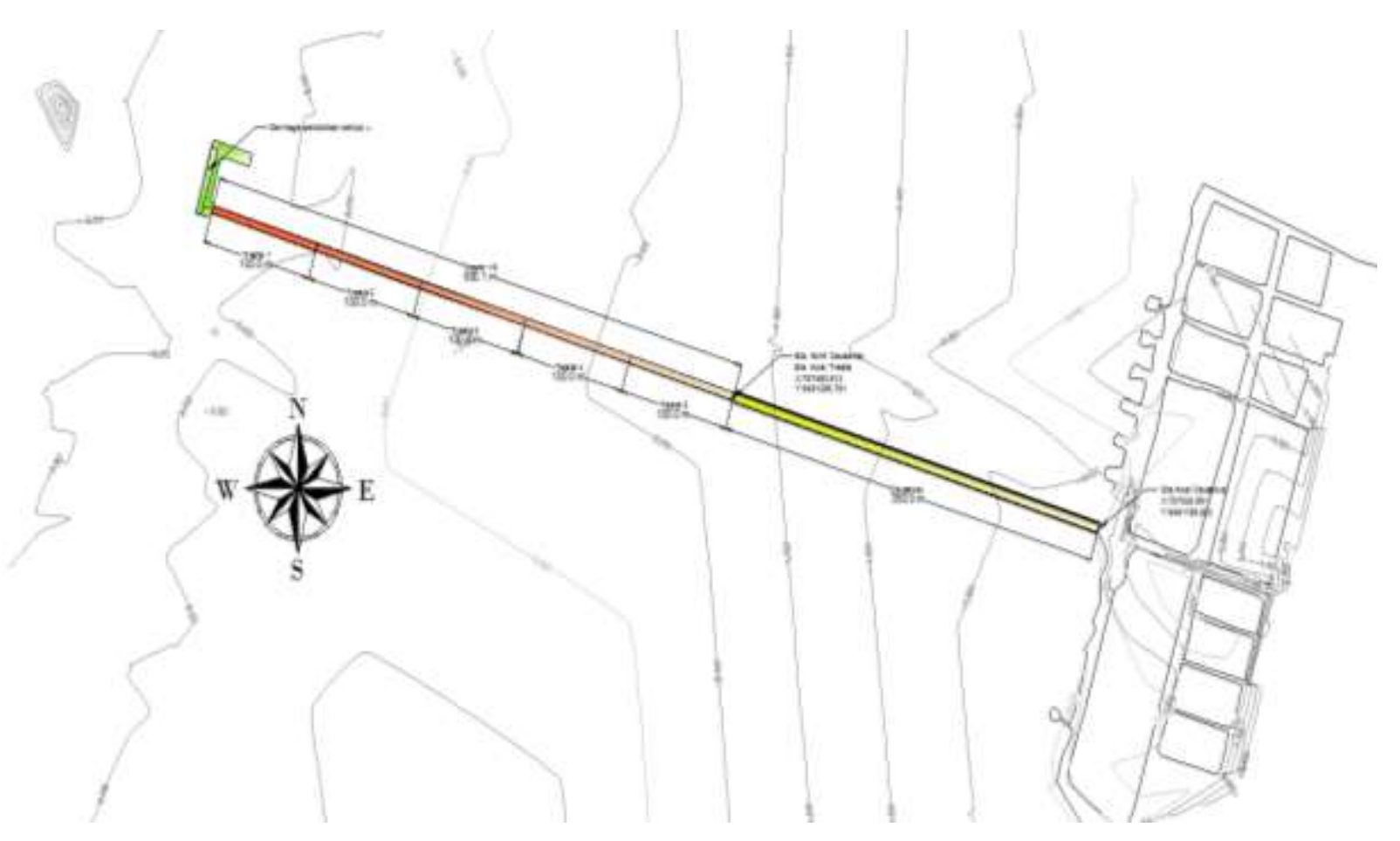

Gambar 1. Layout dermaga pendidikan

\subsection{SARAN}

\section{KESIMPULAN DAN SARAN \\ 4.1 KESIMPULAN}

1. Hasil analisis survei batimetri menunjukkan bahwa perairan lokasi dermaga pendidikan Politani sangat landai dan panjang kelandaian cukup jauh kedepan arah laut. Kemiringan garis pantai sampai \pm 400 meter ke arah laut masih sangat kecil yakni hanya sekitar $0,43 \%$. Area kiri dan kanan jetti atau groin eksisting juga sangat landai dengan kemiringan kurang lebih sama.

2. Pengukuran pada radius 800 meter dari garis pantai baru menunjukkan kedalaman yang cukup besar yakni sekitar 3,00 sampai 4,00 meter. Berdasarkan pertimbangan tunggang pasang surut yakni sekitar 2,03 meter dan draft kapal maksimal 1,5 meter maka dermaga harus jauh menjorok ke laut (model jetty) yakni sampai pada jarak 850 meter dari garis pantai dengan kondisi kedalaman 3,5 meter dari LWS
Disarankan untuk melakukan penelitian lanjutan terkait Analisis mengenai dampak lingkungan untuk menjadi dermaga pendidikan yang baik di Politeknik Pertanian Negeri Pangkep.

\section{UCAPAN TERIMA KASIH}

Terima kasih penulis sampaikan kepada Direktur Politeknik Pertanian Negeri Pangkajene dan Kepulauan beserta jajarannya dan Ketua Pusat Penelitian dan Pengabdian Masyarakat Politeknik Pertanian Negeri Pangkajene dan Kepulauan yang telah menyediakan dana untuk pelaksanaan penelitian ini melalui anggaran biaya penerimaan Negara bukan pajak (PNBP) tahun anggaran 2019

\section{DAFTAR PUSTAKA}


Triatmadja R. (2007)).Pengantar Teknik

Pantai.Diktat Kuliah S2 FT UGM.Yogyakarta.

Triatmodjo B. (1999). Teknik Pantai. Beta Offset. Yogyakarta.

Setyandito O dkk. ( 2007). Analisa Erosi Dan Perubahan Garis Pantai Pada Pantai Pasir

Buatan Dan Sekitarnya Di Takisung, Propinsi Kalimantan Selatan.Jurnal Teknik Sipil Fakultas Teknik Universitas Mataram,Vol 7,No.3.Mataram

Adur, SA., 2011, Evaluasi Posisi Dermaga Pelabuhan Merak Ditinjau dari Aspek Manuver Kapal dan Kondisi Lingkungan, (Tugas akhir), Universitas Indonesia, Depok.

Triatmodjo, B., 1992, Pelabuhan, Beta Offset, Yogyakarta.

Kramadibrata, S., 1985, MerancangMerancang Pelabuhan, Geneca Exact, Bandung.

CERC, 1984, Shore Protection Manual Volume I, US Army Coastal Engineering Research Center, Washington.

Nur Yuwono., 1994, Perancangan Bangunan Jetty, Laboratorium Hidraulika dan Hidrologi, PAU-IT-UGM, Yogyakarta. 